\title{
A study on the synthesis, characterization and catalytic activity of ruthenium-substituted MFI (Mobil Five) zeolite
}

\author{
KISHOR KR SHAH ${ }^{1, *}$ and ANUP K TALUKDAR ${ }^{2}$ \\ ${ }^{1}$ Department of Chemistry, ADP College, Nagaon 782002, India \\ ${ }^{2}$ Department of Chemistry, Gauhati University, Guwahati 781014, India \\ *Author for correspondence (kishore_shah14@yahoo.com)
}

MS received 13 October 2016; accepted 13 March 2017; published online 23 November 2017

\begin{abstract}
Hydrothermal synthesis was adapted to prepare a series of ruthenium (Ru)-incorporated Mobil Five (MFI) zeolite materials with silicon $(\mathrm{Si})$ to aluminium (Al) ratio of 100 and with $\mathrm{Al}$ to $\mathrm{Ru}$ ratios 1:1, 2:1 and 3:1. An X-ray diffractometer (XRD) and FT-IR were employed to identify the formation of the zeolite phase. A favourable environment was maintained in the gel to overcome the difficulties of isomorphous substitution of ruthenium into the MFI framework. The unit cell volume change and the shift in XRD reflection positions showed a positive correlation with increased ruthenium content in the samples. UV-Vis (DRS) spectra confirmed the position of ruthenium in the T-site in the MFI structure. Thermogravimetric analysis was carried out for studying water and template removal patterns and also for studying the thermal stability of the synthesized samples. Formation of uniform rectangle- and twinned-rectangle-shaped MFI particles with particle size approaching $27 \mu \mathrm{m}$ was confirmed by scanning electron microscopy. Energy-dispersive X-ray analysis was carried out for quantification of $\mathrm{Si}, \mathrm{Al}$ and $\mathrm{Ru}$. The catalytic activities of the synthesized samples for the hydroxylation of phenol was investigated, the major products being catechol and hydroquinone.
\end{abstract}

Keywords. MFI; ruthenium; catechol.

\section{Introduction}

The possibility of insertion of other metal ions such as $\mathrm{Ru}^{3+}$, $\mathrm{Fe}^{3+}, \mathrm{Zr}^{4+}, \mathrm{Ti}^{4+}, \mathrm{In}^{3+}, \mathrm{Ga}^{3+}$, etc. into zeolite sites leads to modification of some important properties such as structural features, surface area, crystallinity, pore size, acidity, shape selectivity and catalytic properties. Consequently, in recent times, there has been interest in this area from the perspective of heterogeneous catalysis. Modified zeolites are finding more applications as heterogeneous catalysts as compared with the unmodified ones [1]. Isomorphous substitution of $\mathrm{Si}$ atoms by trivalent atoms from Group $13(\mathrm{Al}, \mathrm{Ga}, \mathrm{B})$ and Group $8(\mathrm{Fe})$ into the crystalline framework of MFI-silicalites has been reported to modify Brönsted acid sites. Such materials can be effectively used as catalysts applied to different organic reactions. The migration of heteroatoms into extra framework positions and dihydroxylation induced by the thermal and hydrothermal treatment of the zeolites can result in the generation of Lewis acid sites on the surface of the zeolites in addition to Brönsted acid sites [2]. If zeolites are modified by isomorphous replacement of $\mathrm{Al}$ or $\mathrm{Si}$ with transition metals, we can generate redox active sites in the zeolite structure $[3,4]$. Literature is available relating to the introduction of $\mathrm{Fe}$ in zeolite at different structural positions [5]. However, very few reports are available [6] on introduction of ruthenium into zeolite and only one paper is related to isomorphous substitution of ruthenium [7].
Ruthenium also has, like iron, a tendency to form insoluble hydroxides in a basic environment. The extraordinarily high catalytic activity of Ru containing materials has drawn the attention of the researchers [8-10]. It can efficiently catalyse the oxidation of $\mathrm{CO}$ with $\mathrm{O}_{2}$ below room temperature [10-12]. The existence of co-ordinatively unsaturated ruthenium species is attributed to the outstanding catalytic activity of $\mathrm{RuO}_{2}$ [8]. Different electronic, magnetic, catalytic, optical and other properties are observed for nanometre-sized materials compared with the corresponding bulk materials [13]. The nanomaterials can be used as novel catalysts due to their large surface area and high density of active sites.

In the present study, ruthenium is introduced into the T-site of MFI zeolite, at least partially, in slightly alkaline medium using ruthenium (III) chloride.

The materials have been tested as catalysts for phenol oxidation into catechol (CL) and hydroquinone (HQ), which are very highly valued phenolic derivatives on the industrial scale. They are used as starting materials for pharmaceuticals, perfumes and many fine chemicals. CL and HQ are also used in photography and as antioxidants and polymerization inhibitors as well as in pesticides and flavouring agents [14]. Like other oxidation reactions, phenol hydroxylation has been usually carried out using stoichiometric oxidants. Due to problems associated with such previous methodologies, one of the major goals of current research is the replacement of processes using wasteful and toxic stoichiometric oxidants 
with routes based upon more environment-friendly technologies. Therefore, direct phenol hydroxylation with $\mathrm{H}_{2} \mathrm{O}_{2}$ is of contemporary interest.

\section{Experimental}

\subsection{Synthesis of MFI zeolites}

In this work, Ru-incorporated MFI zeolites were synthesized with an $\mathrm{Si}$ to $\mathrm{Al}$ and $\mathrm{Ru}$ mole ratio of 100 and $\mathrm{Al}$ to $\mathrm{Ru}$ ratios of $1: 1,2: 1$ and $3: 1$. The chemicals used in the synthesis procedure were tetrapropylammonium bromide (TPA-Br, Lancaster), sodium aluminate (Kemphasol), sodium fluoride (Fluka Chemika 99\%), ruthenium chloride (Merck), fumed silica $(\mathrm{BDH})$ and de-ionized water.

Molar ratios of the components in the gel with other conditions maintained during the synthesis of the MFI zeolite samples with $\mathrm{Si}:(\mathrm{Al}+\mathrm{Ru})$ ratio of 100 and $\mathrm{Al}: \mathrm{Ru}$ ratio of $1: 1$ are given as follows:

$\mathrm{Si}: \mathrm{Al}=100: 0.5, \mathrm{NaF}: \mathrm{SiO}_{2}=1, \mathrm{SiO}_{2}: \mathrm{Al}_{2} \mathrm{O}_{3}=200$, TPA-Br: $\mathrm{SiO}_{2}=0.07, \mathrm{H}_{2} \mathrm{O}: \mathrm{SiO}_{2}=80, \mathrm{Si}: \mathrm{Ru}=100: 0.5$.

For the synthesis of the zeolite samples with the compositions of interest, the required amount of $\mathrm{NaF}$ was dissolved slowly in $23 \mathrm{ml}$ of de-ionized $\mathrm{H}_{2} \mathrm{O} ; 1.551 \mathrm{~g}$ of TPA-Br (template) was added slowly to this solution with continuous stirring. After stirring the solution for about $15 \mathrm{~min}, 1.2947 \mathrm{~g}$ of $\mathrm{SiO}_{2}$ (source of $\mathrm{Si}$ ) was added slowly to this mixture. The resulting mixture (A) was stirred for a further $30 \mathrm{~min}$.

A calculated amount of $\mathrm{NaAlO}_{2}$ (source of $\mathrm{Al}$ ) was dissolved in 97 mlof de-ionized water slowly. The solution was stirred for a further $10 \mathrm{~min}$ after addition of desired amount of ruthenium chloride (source of $\mathrm{Ru}$ ). To this solution, $3.705 \mathrm{~g}$ of $\mathrm{SiO}_{2}$ was also added slowly with continuous stirring. The resultant mixture (B) was stirred thoroughly for a further $30 \mathrm{~min}$. To get a homogeneous gel, the mixture A was added to mixture B slowly and stirred continuously for $3 \mathrm{~h}$. The $\mathrm{pH}$ of the gel was maintained in the range 6-7.

The gel was then placed inside a teflon-lined stainless-steel autoclave and heated for $25 \mathrm{~h}$ at $473 \mathrm{~K}$ in an oven. The product was then cooled, filtered (Whatman Number 42) and washed with de-ionized water several times. The synthesized sample was dried at room temperature for about $12 \mathrm{~h}$ and at $383 \mathrm{~K}$ for $6 \mathrm{~h}$. The template in the sample was removed by calcination at $753 \mathrm{~K}$. Using a similar procedure, further samples of $\mathrm{Ru}$-incorporated $\mathrm{MFI}$ zeolite with different $\mathrm{Al}: \mathrm{Ru}$ ratios were synthesized. The molar ratios of the components in the gel, the sample designation and other conditions maintained during the synthesis of the zeolite samples are presented in table 1 . For the synthesis of parent MFI, a similar procedure was used, except for the use of the ruthenium salt.

\subsection{Hydroxylation of phenol with the synthesized catalysts (catalytic activity)}

In this study, reactions between phenol and $\mathrm{H}_{2} \mathrm{O}_{2}$ were carried out in the presence of synthesized samples and in the presence of solvent (scheme 1). CL, HQ and parabenzoquinone are the possible products. The reaction of phenol hydroxylation is a liquid-phase reaction and was carried out in a three-necked round bottom flask equipped with a reflux condenser. The

Table 1. Designation of the samples and molar ratios of the components in the gel with other conditions maintained during the synthesis of the MFI zeolite samples (TPA-Br:SiO $2=0.07, \mathrm{NaF}: \mathrm{SiO}_{2}=1$ and $\left.\mathrm{H}_{2} \mathrm{O}: \mathrm{SiO}_{2}=80\right)$.

\begin{tabular}{lccccc}
\hline & \multicolumn{2}{c}{ In the gel } & & & \multicolumn{2}{c}{ In the sample (calculated from EDX) } \\
\cline { 2 - 3 } $\begin{array}{l}\text { Sample } \\
\text { designation }\end{array}$ & $\mathrm{Si}:(\mathrm{Al}+\mathrm{Ru})$ or Si:Al & $\mathrm{Al}: \mathrm{Ru}$ & $\mathrm{pH}$ of the gel & $\mathrm{Si}:(\mathrm{Al}+\mathrm{Ru})$ or Si:Al & $\mathrm{Al}: \mathrm{Ru}$ \\
\hline S100Ru1 & 100 & $1: 1$ & 7.0 & 136 & $1.3: 1$ \\
S100Ru2 & 100 & $2: 1$ & 6.9 & 138 & $1.5: 1$ \\
S100Ru3 & 100 & $3: 1$ & 6.8 & 142 & $2.2: 1$ \\
S100 & 100 & - & 6.9 & 132 & - \\
\hline
\end{tabular}

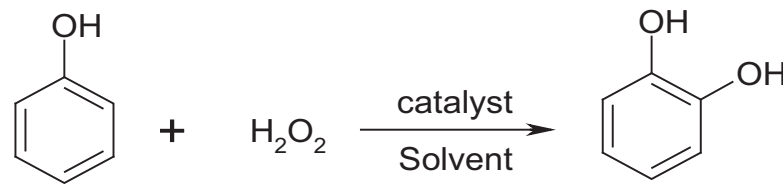

Catechol (CL)<smiles>Oc1ccc(O)cc1</smiles>

Hydroquinone (HQ)<smiles>O=C1C=CC(=O)C=C1</smiles>

Benzoquinone

Scheme 1. Hydroxylation of phenol. 
reaction was studied in the temperature range 333-353 $\mathrm{K}$ and in different solvents such as water and acetonitrile. To maintain the temperature, the reactions were carried out in a thermostatted oil bath. The catalysts were filtered and dried after each experiment. The catalysts were reused after calcination in air at $753 \mathrm{~K}$ for $6 \mathrm{~h}$. The synthesized catalysts were found to be effective even after two runs. The reaction mixtures were analysed by gas chromatography.

In the present study, the formation of parabenzoquinone was not detected due to the low levels of its production. Phenol conversion and the selectivities of CL and HQ were calculated using equations (1), (2) and (3), respectively:

$$
\begin{aligned}
& \text { Phenol conversion }(\%)=\left[\left(\text { mole of phenol }_{\text {inlet }}\right.\right. \\
& \left.\left.\quad-\text { mole of phenol }_{\text {outlet }}\right) / \text { mole of phenol }_{\text {inlet }}\right] \times 100,
\end{aligned}
$$

$$
\begin{aligned}
& \text { Selectivity for CL }(\%) \\
& =[(\text { mole of } \mathrm{CL} / \text { mole of } \mathrm{CL}+\text { mole of } \mathrm{HQ}] \times 100,
\end{aligned}
$$

$$
\begin{aligned}
& \text { Selectivity for HQ }(\%) \\
& =[(\text { mole of } \mathrm{HQ} / \text { mole of } \mathrm{CL}+\text { mole of } \mathrm{HQ}] \times 100 \text {. }
\end{aligned}
$$

\subsection{Characterization of the materials}

A Miniflex Advance X-ray diffractometer (XRD) with $\mathrm{Cu}-\mathrm{K}_{\alpha}$ radiation of wavelength $1.5418 \AA$ operated at voltage $=30 \mathrm{kV}$ and current $=15 \mathrm{~mA}$ was used for powder XRD measurement. During analysis the XRD data were collected in the $2 \theta$ range $5-50^{\circ}$ with a step size $0.05^{\circ}$ and a counting time of $0.5 \mathrm{~s}$ per step. The FT-IR spectra of the samples were recorded using $\mathrm{KBr}$ pellets in mid-IR region of $1500-450 \mathrm{~cm}^{-1}$ with resolution $8 \mathrm{~cm}^{-1}$ using a Perkin Elmer RX 1 FT-IR spectrophotometer. The thermogravimetric analysis (TGA) data of the samples were recorded using a Mettler Toledo TG analyser $($ model $=$ TGA/DSC -1$)$. The analysis was carried out at a heating rate of $10 \mathrm{~K} \mathrm{~min}^{-1}$ in $\mathrm{N}_{2}$ flow over the temperature range of 313-1023 K. A U-4100 spectrophotometer (solid) was used for the recording of the UV-Vis spectra of the samples, applying a sampling interval of $2.00 \mathrm{~nm}$ and a scan speed of $600 \mathrm{~nm} \mathrm{~min}{ }^{-1}$; the spectra of the samples were recorded in the wavelength range $200-600 \mathrm{~nm}$. A Micromeritics (Tristar 3000) analyser with $\mathrm{N}_{2}$ as adsorbate at $-195.85^{\circ} \mathrm{C}$ was used for the determination of specific surface area, pore volume and porosity of the samples. Prior to the measurement by the BET method (single point, $p / p_{0}=0.13$ ) the samples were degassed at $673 \mathrm{~K}$ for $6 \mathrm{~h}$. A Jeol JSM-6390 LV scanning electron microscope (SEM) was used for the study of morphology of the synthesized samples. For the determination of elemental composition of calcined sample, energy-dispersive $\mathrm{X}$-ray analysis (EDX) was carried out at $20 \mathrm{kV}$. Measurement was applied to a number of areas and the values were normalized to get average values. Finally, GC-MS (Perkin Elmer,
Clarus-500) was used for the identification of the reaction products of phenol hydroxylation reaction.

\section{Results and discussion}

Very good agreement was observed when both the $d$-spacing and relative intensities in the XRD patterns of the synthesized $\mathrm{Ru}-\mathrm{MFI}$ samples were compared to those reported in the literature [15]. The XRD patterns of Ru-MFI samples synthesized using different aluminium to ruthenium ratios are presented in figure 1 . The formation of pure phase zeolite was confirmed by the XRD patterns, which presented prominent peaks in $2 \theta$ values around 6.5 and 22.5 with a few additional shoulder peaks in all the ruthenium incorporated MFI samples. Moreover, as the $\mathrm{Ru}^{3+}$ ion has a larger ionic radius $(0.69 \AA)$ than that of $\mathrm{Al}^{3+}(0.57 \AA)$, the expansion of the unit cell confirms the incorporation of ruthenium within the framework. As the level of metal substitution increases, the unit cell volumes were also found to increase gradually.

It was further noticed that the major reflections shift towards lower $2 \theta$ values with increasing level of metal substitution, indicating the successful incorporation of ruthenium into the framework of MFI [16]. Table 2 shows the shift in the (501) reflection $2 \theta$ value of the $\mathrm{Ru}-\mathrm{MFI}$ samples with respect to the parent MFI.

For a particular crystallographic plane $(h k l)$, the crystallinity of the MFI samples can be calculated using the following relation:

$$
C(\%)=100 \times I_{h k l} /\left(I_{\mathrm{b}}+I_{h k l}\right),
$$

where $I_{\mathrm{b}}$ is the integral background intensity and $I_{h k l}$ is the corrected integral XRD peak intensity for the same plane.

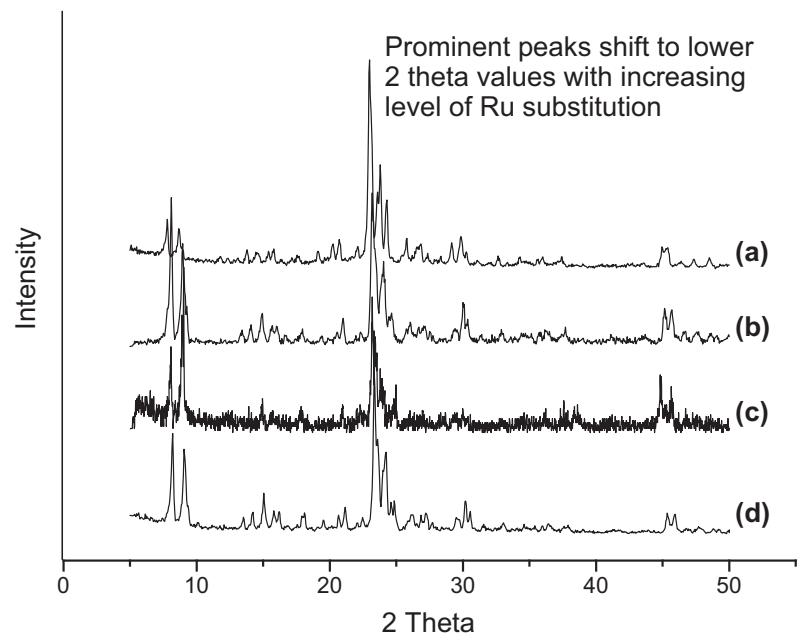

Figure 1. XRD patterns of the synthesized samples: (a) S100Ru1, (b) S100Ru2, (c) S100Ru3 and (d) S100. 
Table 2. Shift in $2 \theta$ value of the (501) reflection of the Ru-MFI samples with respect to parent MFI.

\begin{tabular}{lccc}
\hline Sample & $\begin{array}{l}\mathrm{Ru}^{3+}(\mathrm{mol}) \\
\text { in the gel }\end{array}$ & $\begin{array}{l}\text { Position of the } \\
\text { prominent (501) } \\
\text { peak }\end{array}$ & $\begin{array}{l}\text { Shift in the 2 } \\
\text { value wrt parent } \\
\text { MFI }\end{array}$ \\
\hline S100 & - & 23.36 & - \\
S100Ru1 & 0.50 & 23.07 & 0.29 \\
S100Ru2 & 0.33 & 23.19 & 0.17 \\
S100Ru3 & 0.25 & 23.22 & 0.17 \\
\hline
\end{tabular}

Table 3 contains the crystallinity (\%) with reference to three significant peaks (101), (501) and (303) and the average crystallinity (\%) of the samples. A high crystallinity of $\sim 91 \%$ was found to be exhibited by all the samples in the present investigation.

The crystallite dimension $\left(D_{h k l}\right)$ of the identified crystalline phase was determined by application of the Scherrer formula [17]:

$$
D_{h k l}=K \lambda /(\beta \cos \theta),
$$

where $\theta_{h k l}$ is the Bragg angle, $\lambda$ is the wavelength $\left(\mathrm{CuK}_{\alpha}\right.$, $1.5418 \AA$ ), $\beta$ is the full-width at half-maximum and $K$ is the shape factor (taken to be 0.9 ). For the conversion of $\beta$ from degrees to radians to obtain $D_{h k l}$ in units of nm the factor 5.73 is used. The crystallite sizes of the synthesized samples are found to be in the range $53-57 \mathrm{~nm}$. Table 3 contains the change in unit cell volume of the samples with increasing level of ruthenium substitution in the framework of MFI. With increasing level of ruthenium substitution, the unit cell volumes are also found to increase, i.e., the volume of the unit cells of various samples follows the order

$$
\text { MFI }<\text { S100Ru3 }<\text { S100Ru2 }<\text { S100Ru1 }
$$

FT-IR spectra of synthesized Ru-MFI samples are shown in figure 2. Distinct IR bands near $1080 \mathrm{~cm}^{-1}$ (internal asymmetric stretch), $790 \mathrm{~cm}^{-1}$ (external symmetric stretch), $540 \mathrm{~cm}^{-1}$ (double-ring vibration) and $450 \mathrm{~cm}^{-1}$ (T-O bending) confirm the formation of MFI zeolite in all cases shown. The presence of double five-member rings in the structure is confirmed by the absorption bands near $550 \mathrm{~cm}^{-1}$ [18]. The band around $1225 \mathrm{~cm}^{-1}$ is assigned to four chains of five-member rings arranged around a two-fold screw axis. However, in the present study, the distortion in the spectral pattern with increasing levels of substitution was not to be found similar to that reported previously [17]. An additional absorption peak was observed at $990 \mathrm{~cm}^{-1}$ for Ru-incorporated MFI samples, which is an indication of successful incorporation of Ru into the zeolite framework [19]. This peak is missing in case of the parent non-Ru-containing MFI zeolite. The relative sharpness of this shoulder increases with increasing ruthenium content in the gel. Slight shifts are also observed in the asymmetric and symmetric stretching vibrations and the $\mathrm{T}-\mathrm{O}$ bending, which may be due to incorporation of ruthenium into the MFI framework.

Figure 3 shows the TGA curves of the synthesized RuMFI zeolites. The initial mass loss due to physically adsorbed water in the porous materials was observed up to $423 \mathrm{~K}$ [20]. Table 4 shows the decreasing mass loss in this region with increasing $\mathrm{Ru}$ content. It reflects weaker $\mathrm{Ru}^{3+}-\mathrm{H}_{2} \mathrm{O}$ interaction than $\mathrm{Al}^{3+}-\mathrm{H}_{2} \mathrm{O}$ interaction due to lower charge:radius ratio [7]. With increasing ruthenium concentration in the gel, the mass loss was found to increase in the temperature range $423-893 \mathrm{~K}$, while it was found to decrease at temperatures beyond $893 \mathrm{~K}$. TPA ${ }^{+}$cations ion-paired to crystal surface defects and occluded in zeolite channels are less strongly bound and hence more easily lost in a comparatively lower temperature range (423-893 K). On the other hand, the $\mathrm{TPA}^{+}$cations that are coordinated to $\mathrm{MO}_{4}^{-}$are lost at high temperature above $893 \mathrm{~K}$ as they are strongly bounded.

There is a distinct effect of ruthenium incorporation into MFI structure that is reflected in the increase and decrease of weight loss as ruthenium content increases in the temperature range of 423-773 and beyond $893 \mathrm{~K}$, respectively.

Figure 4 shows the UV-Vis DR spectra of the Ru-MFI samples. All the spectra of Ru-MFI samples show a band around $212 \mathrm{~nm}$, which is missing in case of the parent MFI sample. The band at around $212 \mathrm{~nm}$ is an indication of a heteroatom with tetrahedral coordination [21]. However, an additional peak around $250 \mathrm{~nm}$ is an indication of the presence of some extra framework $\mathrm{Ru}$.

Table 3. Crystallite size, percentage of crystallinity $C_{h k l}(\%)$ and unit cell volume of the synthesized Ru-MFI sample from

\begin{tabular}{|c|c|c|c|c|c|c|c|c|c|c|c|}
\hline \multirow[b]{2}{*}{ Sample } & \multirow{2}{*}{$\begin{array}{l}\text { Si:Al or } \\
\text { Si:(Al+Ru) }\end{array}$} & \multirow[b]{2}{*}{$\mathrm{Al}: \mathrm{Ru}$} & \multirow{2}{*}{$\begin{array}{l}\text { Crystallite size } \\
\text { from }(501)(\mathrm{nm})\end{array}$} & \multicolumn{3}{|c|}{$C(\%)$ from XRD } & \multirow[b]{2}{*}{ Average } & \multicolumn{3}{|c|}{ Unit cell edges $(\AA)$} & \multirow{2}{*}{$\begin{array}{c}\text { Unit cell } \\
\text { volume }\left(\AA^{3}\right)\end{array}$} \\
\hline & & & & (101) & $(501)$ & (303) & & $a$ & $b$ & $c$ & \\
\hline S100Ru1 & 100 & 1 & 53 & 87.90 & 92.47 & 89.54 & 89.97 & 13.98 & 19.85 & 14.96 & 4151.44 \\
\hline $\mathrm{S} 100 \mathrm{Ru} 2$ & 100 & 2 & 54 & 94.94 & 94.51 & 91.08 & 93.51 & 13.91 & 19.79 & 14.91 & 4104.41 \\
\hline S100Ru3 & 100 & 3 & 57 & 90.99 & 95.59 & 87.02 & 91.20 & 13.74 & 19.76 & 14.79 & 4015.52 \\
\hline $\mathrm{S} 100$ & 100 & - & 49 & 91.43 & 95.78 & 87.65 & 91.62 & 13.59 & 19.71 & 14.64 & 3921.45 \\
\hline
\end{tabular}
XRD. 
Figure 5 shows the nitrogen adsorption isotherms of calcined Ru-MFI samples. H-1-type hysteresis loops are observed for the ruthenium-incorporated zeolite samples with adsorption-desorption branches at $p / p_{0}=0.12-0.21$. It was observed that with increase in $\mathrm{Ru}$ content in the gel from 0.25 to $0.50 \mathrm{M}$ the specific surface area of the $\mathrm{Ru}-$ MFI samples increased from $\sim 359$ to $\sim 364 \mathrm{~m}^{2} \mathrm{~g}^{-1}$ and the pore volume increased from 0.179 to $0.188 \mathrm{~cm}^{3} \mathrm{~g}^{-1}$. The results reflect that the surface area as well as the pore volume increased with the increase in the level of substitution of ruthenium. Specific surface area, pore size and pore volume of synthesized $\mathrm{Ru}-\mathrm{MFI}$ samples are presented in table 4 . The pore sizes of the synthesized samples were found to be in both the microporous as well as in the mesoporous range.

SEM micrographs of synthesized $\mathrm{Ru}-\mathrm{MFI}$ samples are shown in figure 6 . The micrographs indicate the formation of quite uniform rectangle- and twinned-rectangle-shaped $\mathrm{Ru}-\mathrm{MFI}$ particles with particle size of nearly $27 \mu \mathrm{m}$. The

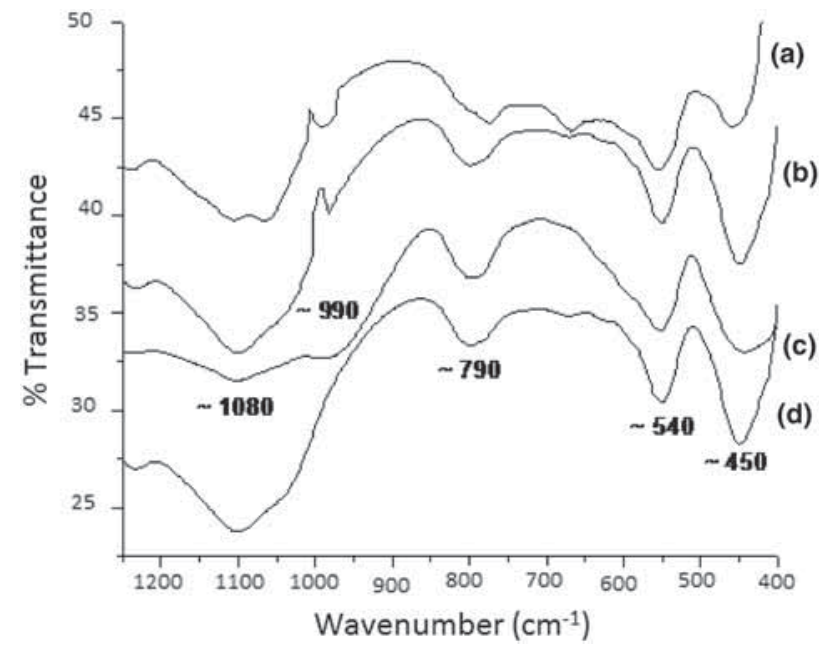

Figure 2. FT-IR spectra of (a) S100Ru1, (b) S100Ru2, (c) S100Ru3 and (d) S100. difference in the metal concentration in the gel is not reflected in the morphological features of the samples. However, the shape and size of Ru-MFI samples are markedly different from those of undoped MFI (figure 6d). Greater agglomeration of the particles is noticed for samples containing lesser $\mathrm{Ru}$, which may be due to residual silica remaining during the crystallization process. With increase in the metal concentration in the gel the crystallinity and crystallite size are also found to increase.

Parent (sample S100) and modified Ru-MFI samples (samples S100Ru1, S100Ru2 and S100Ru3) were used to carry out the phenol hydroxylation reactions in the temperature range $333-353 \mathrm{~K}$ with $30 \% \mathrm{H}_{2} \mathrm{O}_{2}, 30 \% \mathrm{H}_{2} \mathrm{O}_{2}+$ additional water and $30 \% \mathrm{H}_{2} \mathrm{O}_{2}+$ acetonitrile. A phenol to hydrogen peroxide mole ratio of 1:1 was used. CL was found to be the predominant product, in the present reaction conditions. When the progress of the reaction was monitored with time during the hydroxylation of phenol it was observed that conversion

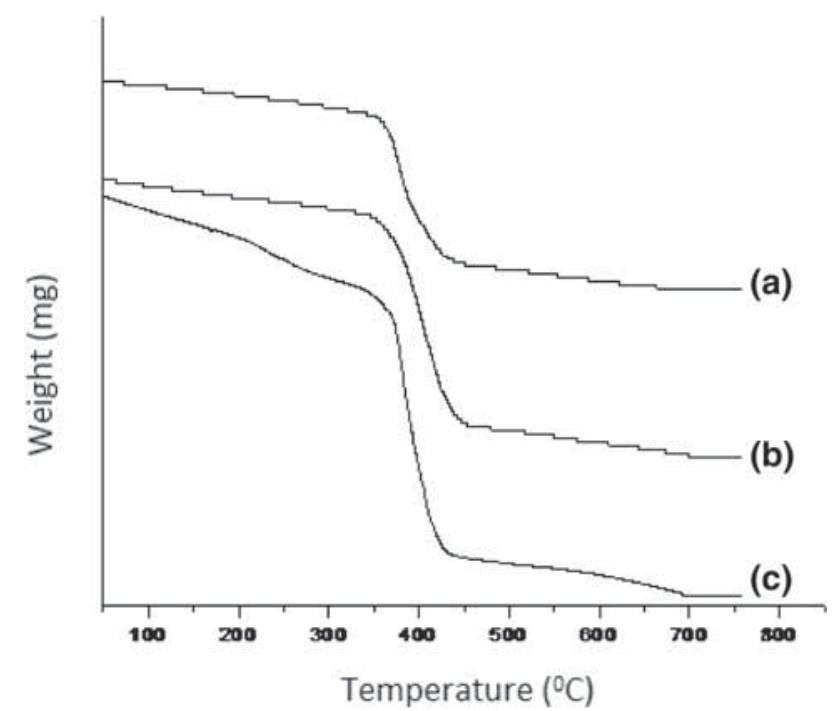

Figure 3. TGA curves of (a) S100Ru1, (b) S100Ru2 and (c) S100Ru3.

Table 4. Specific surface area, pore size, pore volume and weight loss (\%, during TG analysis) of synthesized Ru-MFI samples.

\begin{tabular}{|c|c|c|c|c|c|c|c|c|}
\hline Sample & $\begin{array}{l}\mathrm{Ru}^{3+}(\mathrm{mol}) \\
\text { in the gel }\end{array}$ & $\begin{array}{c}\text { Surface area } \\
(\mathrm{BET})\left(\mathrm{m}^{2} \mathrm{~g}^{-1}\right)\end{array}$ & $\begin{array}{l}\text { Pore volume } \\
\left(\mathrm{cm}^{3} \mathrm{~g}^{-1}\right)\end{array}$ & $\begin{array}{l}\text { Mesopore } \\
\text { size }(\mathrm{nm})\end{array}$ & $\begin{array}{l}\text { Micropore } \\
\text { size }(\mathrm{nm})\end{array}$ & Temp. range & $\begin{array}{l}\text { Weight loss } \\
(\%)\end{array}$ & $\begin{array}{c}\text { Total weight } \\
\text { loss }(\%)\end{array}$ \\
\hline \multirow[t]{3}{*}{ S100Ru1 } & 0.50 & 364 & 0.188 & 2.3 & 0.51 & $313-423$ & 1.06 & 15.19 \\
\hline & & & & & & $423-893$ & 12.67 & \\
\hline & & & & & & $893-1023$ & 1.46 & \\
\hline \multirow[t]{3}{*}{ S100Ru2 } & 0.33 & 360 & 0.184 & 2.1 & 0.52 & $313-423$ & 1.32 & 14.55 \\
\hline & & & & & & $423-893$ & 11.69 & \\
\hline & & & & & & $893-1023$ & 1.54 & \\
\hline \multirow[t]{3}{*}{ S100Ru3 } & 0.25 & 359 & 0.179 & 2.2 & 0.53 & $313-423$ & 1.37 & 14.47 \\
\hline & & & & & & $423-893$ & 11.54 & \\
\hline & & & & & & $893-1023$ & 1.56 & \\
\hline S100 & - & 355 & 0.175 & 2.1 & 0.51 & - & - & - \\
\hline
\end{tabular}


increased with increase of reaction time (figure 7). This was true for all the solvents used in the present study, i.e., with $30 \%$ $\mathrm{H}_{2} \mathrm{O}_{2}, 30 \% \mathrm{H}_{2} \mathrm{O}_{2}+$ additional water and with $30 \% \mathrm{H}_{2} \mathrm{O}_{2}+$ acetonitrile.

On raising the temperature up to 343 from $333 \mathrm{~K}$, the conversion was found to increase (figure 8), but on further raising the temperature up to $353 \mathrm{~K}$, although the conversion was increased, the rate of increase was less in comparison with the rate at $343 \mathrm{~K}$. This observed fact may be

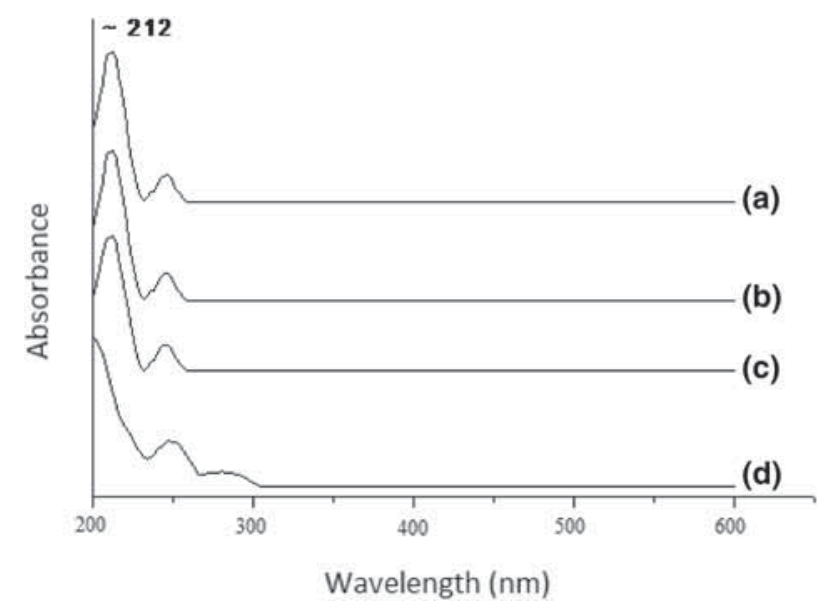

Figure 4. UV-Vis DR spectra of (a) S100Ru1, (b) S100Ru2, (c) S100Ru3 and (d) S100.
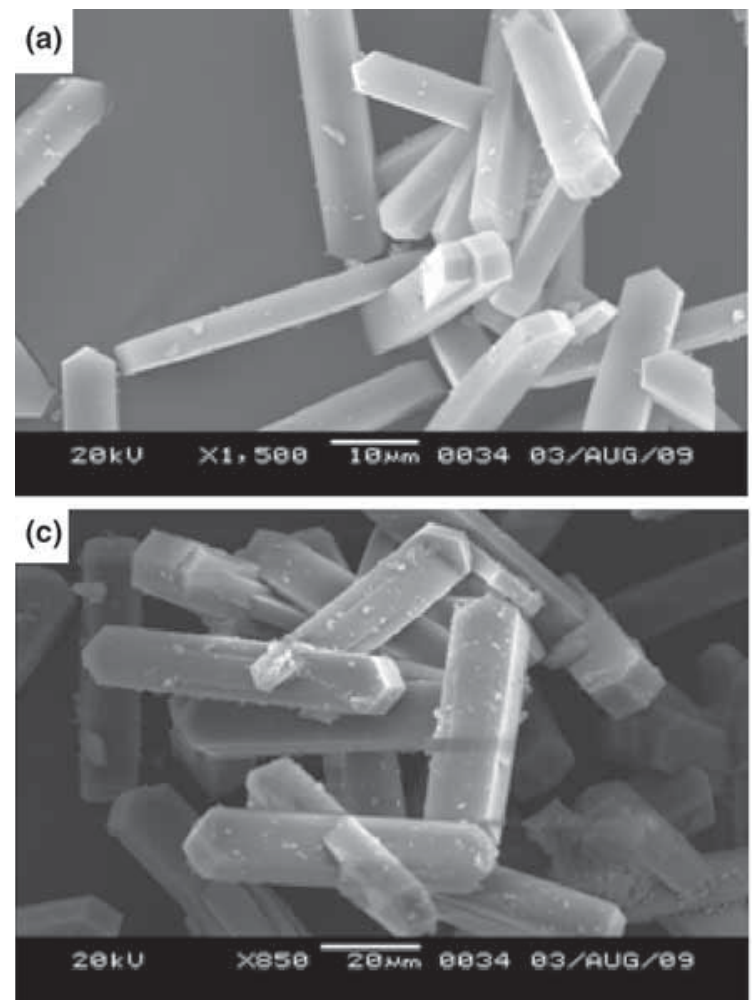

due to the competitive non-selective thermal decomposition of $\mathrm{H}_{2} \mathrm{O}_{2}$ at higher temperature [22]; $30 \% \mathrm{H}_{2} \mathrm{O}_{2}$ used with additional water as solvent was found to be better for phenol conversion in all cases. The conversion of phenol was found to increase with increase in solvent polarity. Probably in polar solvents like $\mathrm{H}_{2} \mathrm{O}$, phenol and $\mathrm{H}_{2} \mathrm{O}_{2}$ can reach the active sites more easily than in organic solvents. For driving the reaction, the hydroxylating agent and the

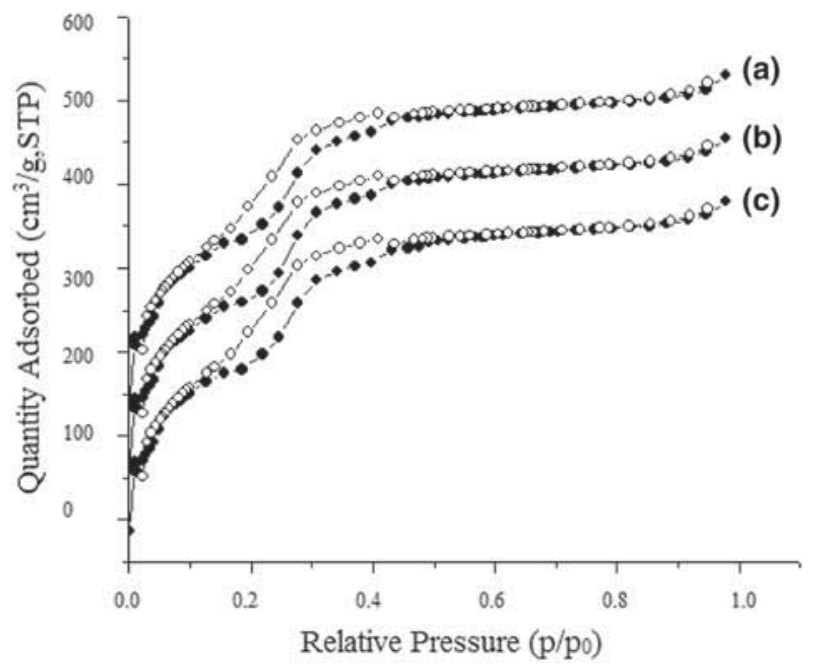

Figure 5. $\mathrm{N}_{2}$ adsorption isotherm of (a) S100Ru1, (b) S100Ru2 and (c) S100Ru3.
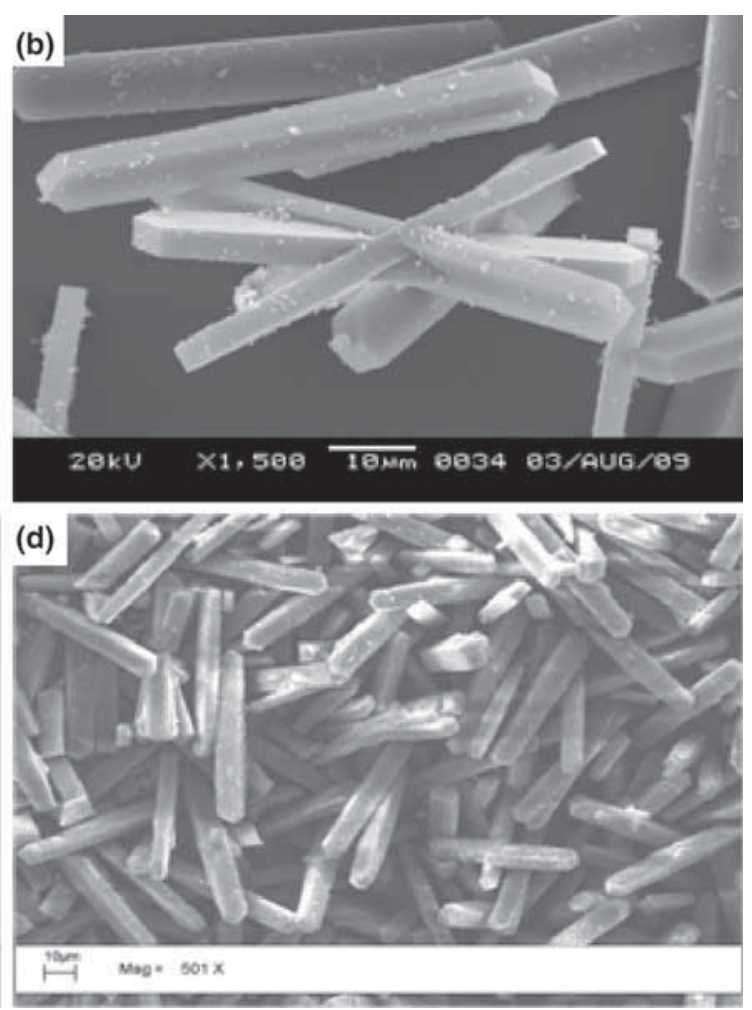

Figure 6. SEM images of (a) S100Ru1, (b) S100Ru2, (c) S100Ru3 and (d) S100. 


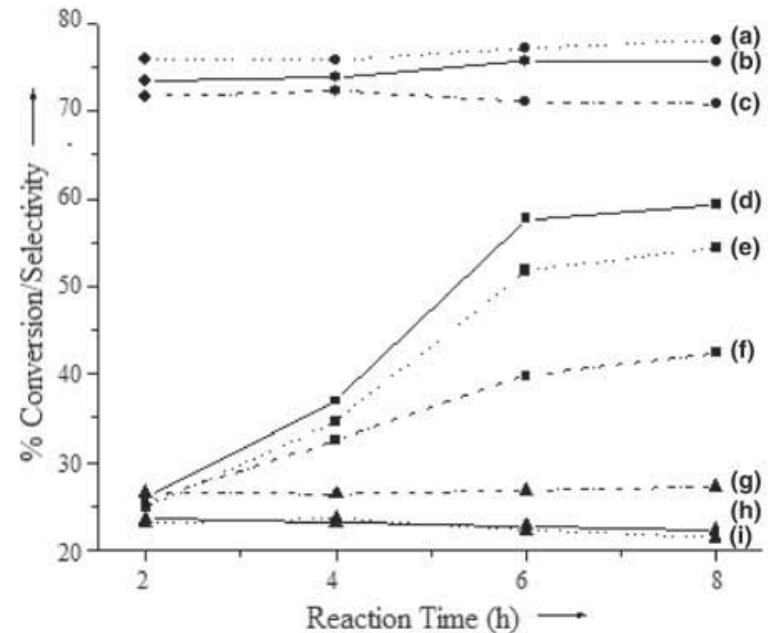
[a] \% Selectivity of $\mathrm{CL}$ in $\mathrm{CH}_{3} \mathrm{CN}$
[b] \% Selectivity of $\mathrm{CL}$ in $\mathrm{H}_{2} \mathrm{O}$
[c] \% Selectivity of CL with no additional solvent [d] \% Conversion of phenol in $\mathrm{H}_{2} \mathrm{O}$
[e] \% Conversion of phenol in $\mathrm{CH}_{3} \mathrm{CN}$ [f] \% Conversion of phenol with no additional solvent
$[\mathrm{g}] \%$ Selectivity of $\mathrm{HQ}$ with no additional solvent
[h] \% Selectivity of $\mathrm{HQ}$ in $\mathrm{H}_{2} \mathrm{O}$
[i] \% Selectivity of $\mathrm{HQ}$ in $\mathrm{CH}_{3} \mathrm{CN}$

Figure 7. Effect of reaction time on hydroxylation of phenol on $\mathrm{S} 100 \mathrm{Ru} 3$ in $\mathrm{H}_{2} \mathrm{O}, \mathrm{CH}_{3} \mathrm{CN}$ and with no additional solvent.

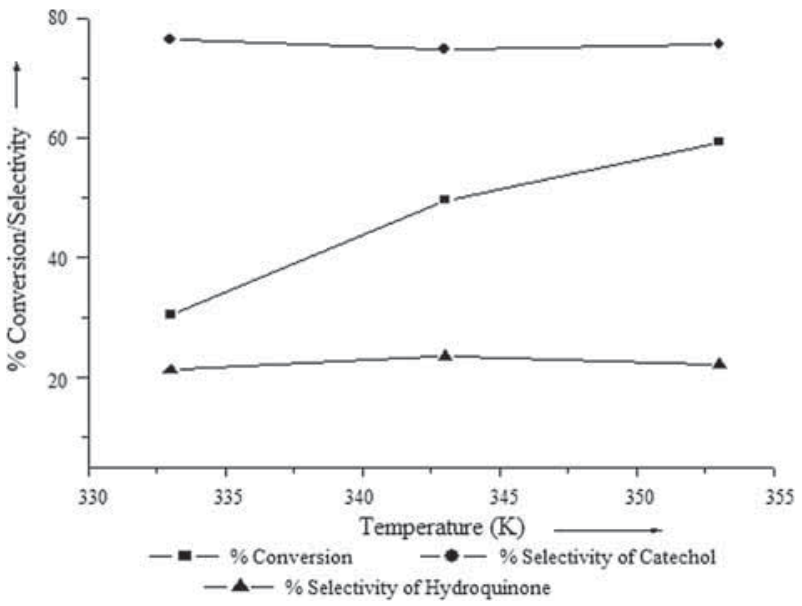

Figure 8. Effect of temperature on hydroxylation of phenol on S100Ru3.

substrate molecule should be near the active site of the catalyst.

In this water medium, the hydroxyl radicals, which are thought to be the active species involved in the hydroxylation reaction, are generated, and both phenol and $\mathrm{H}_{2} \mathrm{O}_{2}$ approach the active centre easily. Moreover, in water, an electrophile is more easily produced and stabilized to a greater degree than in organic solvents. In some organic solvents, the reaction does not take place at all, possibly due to the lack of hydroxylated nature of the organic solvents [23]. In all cases the conversion was found to increase with the increase in the amount

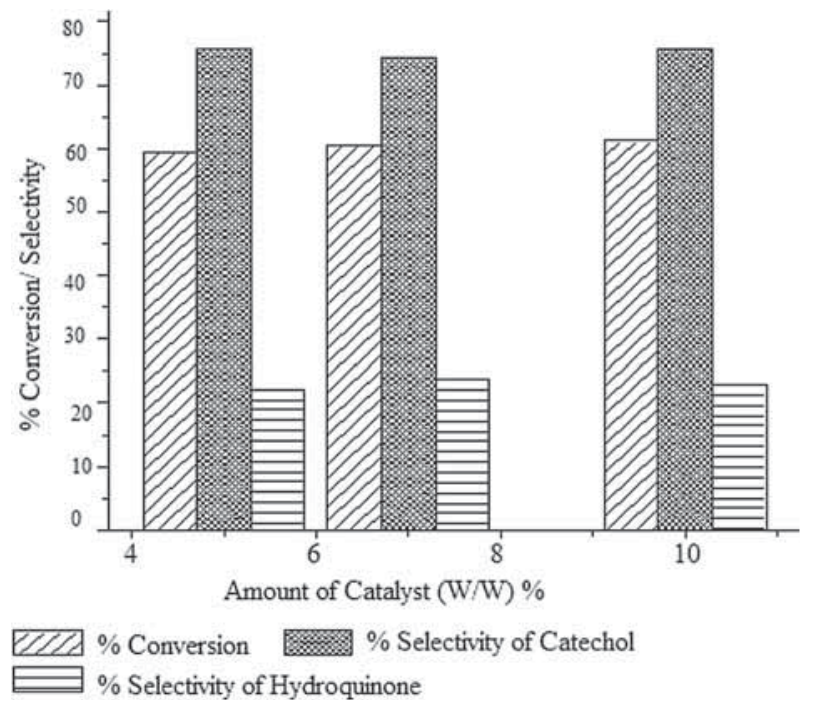

Figure 9. Effect of amount of catalyst on hydroxylation of phenol on S100Ru3.

of catalysts (figure 9). With the increase in the ruthenium content in the synthesized MFI samples the conversion was found to increase. As evident from the decrease of CL/HQ ratio with gradual increase in $\mathrm{Ru}$ content, low $\mathrm{Ru}$ content in the zeolite structure favoured CL formation. After each reaction the catalysts were recovered by filtration and were used for a different set of reactions. It was observed that the performance of the catalyst was not significantly affected even after two runs. The catalysts were hydroxylated during the 
reaction, which on heating undergo dehydration to generate the catalysts.

\section{Conclusion}

Slightly acidic or neutral media were used for the synthesis of ruthenium-incorporated MFI samples using fluoride gel as a mineralizer. The successful formation of MFI zeolite phase was confirmed by XRD and FT-IR spectra of the samples. The successful incorporation of $\mathrm{Ru}$ in MFI samples was confirmed by TGA as well as in the DR spectra; 91\% crystallinity was exhibited for all the synthesized samples of Ru-MFI. With an increasing level of metal substitution the unit cell volumes were found to increase. EDX was carried out for the confirmation of $\mathrm{Si}, \mathrm{Al}$ and $\mathrm{Ru}$ in the synthesized samples. With the increase of ruthenium in the MFI samples, the specific surface area as well as pore volume of the synthesized samples were also found to increase. Although the synthesized samples contain different metal concentrations, their morphological features are found to be almost the same, but their shape and size are noticeably different from those of undoped MFI. Greater agglomeration of the particles is found for the samples containing lesser ruthenium.

In the present work, CL was found to be the predominant product of phenol hydroxylation under the investigated reaction conditions. It was observed that conversion increased with an increase in the amount of Ru in the Ru-MFI samples. With increase in the level of metal content in the samples the $\mathrm{CL} / \mathrm{HQ}$ ratios were found to decrease. The conversion was found to increase with increasing temperature. For conversion of phenol, $30 \% \mathrm{H}_{2} \mathrm{O}_{2}$ with additional water was favourable. With increasing amount of catalyst, the conversion was found to increase in all cases.

\section{Acknowledgements}

We acknowledge Centre for Nanotechnology and CIF of IIT, Guwahati, Department of Physics, Tezpur University, Tezpur, NEHU, Shillong, and Department of Instrumentation and USIC, Gauhati University, for characterization of the samples.

\section{References}

[1] Bekkum H V and Kouwenhoven H W 1989 Rec. Trav. Chim. Pays-Bas 108283

[2] Corma A 1995 Stud. Surf. Sci. Catal. 94736

[3] Williams C D and Latham K 1999 Zeolites and process for preparation thereof US Patent 5925329A; Borade R B 1987 Zeolites 7398

[4] Delmon B 1993 Catal. Lett. 221

[5] Villa A L, Caro C A and de Correa C M 2005 J. Mol. Catal. A: Chem. 228233

[6] Das S K and Dutta P K 1998 Microporous Mesoporous Mater. 22475

[7] Latham K, Thompsett D, Williams C D and Round C L 2000 J. Mater. Chem. C $\mathbf{1 0} 1235$

[8] Over H, Kim Y D, Seitsonen A P, Wendt S, Lundgren E, Schmid M et al 2000 Science 2871474

[9] Madhavaram H, Idriss H, Wendt S, Kim Y D, Knapp M, Over H et al 2001 J. Catal. 202296

[10] Zang L and Kisch H 2000 Angew. Chem. Int. Ed. 393921

[11] Eckle S, Anfang H G and Behm R J 2011 Appl. Catal. A: Gen. 391325

[12] Ali M, Mageed A, Eckle S, Anfang H G and Behm R J 2013 J. Catal. 298148

[13] Goldstein A N 1997 Handbook of nanophase materials (New York: Marcel Dekker)

[14] Tendulkar S B, Tambe S S, Chandra I, Rao P V, Naik R V and Kulkarni B D 1998 Ind. Eng. Chem. Res. 372081

[15] Treacy M M J and Higgins J B (Eds) 2001 Collection of simulated XRD powder patterns for zeolites (Elsevier) p 234

[16] Wangcheng Z, Guanzhong L, Yanglong G, Yun G, Yanqin W, Yunsong W et al 2008 J. Rare Earths 26515

[17] Round C I, Williams C D, Latham K and Duke C V A 2001 Chem. Mater. 13468

[18] Szostak R 1998 Molecular sieve, 2nd edn (London: BlackieAcademic \& Professional) 306, 310, 311

[19] Rakshe B, Ramaswamy V, Hegde S G, Vetrivel R and Ramaswamy A V 1997 Catal. Lett. 4541

[20] Guth J L, Kessler H, Higel J M, Lamblin J M, Patarin J, Seive A et al 1989 ACS Symp. Ser. 398176

[21] Newalkar L B, Johnson O and Komarneni S R 2001 J. Phys. Chem. B $\mathbf{1 0 5} 8356$

[22] Dubey A, Rives V and Kannan S 2002 J. Mol. Catal. A: Chem. 181151

[23] Dubey A, Rives V and Kannan S 2002 J. Mol. Catal. A: Chem. 181155 